\title{
Article
}

\section{The influence of different air-drying conditions on bioactive compounds and antioxidant activity of berries}

Mariela C Bustos, Diego Rocha-Parra, Ines Rueda Sampedro, Sonia de Pascual-Teresa, and Alberto E León J. Agric. Food Chem., Just Accepted Manuscript • DOI: 10.1021/acs.jafc.7b05395 • Publication Date (Web): 02 Mar 2018

Downloaded from http://pubs.acs.org on March 3, 2018

\section{Just Accepted}

"Just Accepted" manuscripts have been peer-reviewed and accepted for publication. They are posted online prior to technical editing, formatting for publication and author proofing. The American Chemical Society provides "Just Accepted" as a service to the research community to expedite the dissemination of scientific material as soon as possible after acceptance. "Just Accepted" manuscripts appear in full in PDF format accompanied by an HTML abstract. "Just Accepted" manuscripts have been fully peer reviewed, but should not be considered the official version of record. They are citable by the Digital Object Identifier (DOI®). "Just Accepted" is an optional service offered to authors. Therefore, the "Just Accepted" Web site may not include all articles that will be published in the journal. After a manuscript is technically edited and formatted, it will be removed from the "Just Accepted" Web site and published as an ASAP article. Note that technical editing may introduce minor changes to the manuscript text and/or graphics which could affect content, and all legal disclaimers and ethical guidelines that apply to the journal pertain. ACS cannot be held responsible for errors or consequences arising from the use of information contained in these "Just Accepted" manuscripts. 
5 1.- Instituto de Ciencia y Tecnología de los Alimentos Córdoba (CONICET - Universidad Nacional de Córdoba).

6 Juan Filloy s/n, Ciudad Universitaria, Córdoba, Argentina.

$7 \quad 2$ - Facultad de Ciencias Agropecuarias, Universidad Nacional de Córdoba. Ciudad Universitaria, Córdoba, Argentina.

83 - Facultad de Ciencias Agrarias, Pontificia Universidad Católica Argentina (UCA), R. Freire 183, Buenos Aires,

9 1426AVC, Argentina.

10 4.- Department of Nutrition and Metabolism, Institute of Food Science, Technology and Nutrition (ICTAN), Consejo

11 Superior de Investigaciones Científicas (CSIC), E, Madrid, Spain.

$12 *$ Corresponding Author: Alberto E. León, E-mail: aeleon@agro.unc.edu.ar. FAX: 54-351-4334118. 


\section{ABSTRACT}

The aim of the present research was to study the effect of convective drying on color, bioactive compounds and antioxidant activity of berry fruits and to chemically characterize the polyphenolic composition of raspberry, boysenberry, redcurrants and blackcurrants fruit. Drying berries at $65{ }^{\circ} \mathrm{C}$ provoked the best conservations of color, particularly for boysenberry and blackcurrant. Drying at $65^{\circ} \mathrm{C}$ was also the condition that showed higher level of polyphenols, while drying at $50{ }^{\circ} \mathrm{C}$ or $130{ }^{\circ} \mathrm{C}$ showed above $\%$ degradation of them due to the long time or high temperature drying. Radical scavenging activity was the predominant antioxidant mechanism in all samples, being 65 ${ }^{\circ} \mathrm{C}$ dried berries the most active ones possibly due to polyphenols depolymerization. The anthocyanin profile showed that delphinidin and cyanidin derivatives were the most abundant anthocyanidins with different predominance between berry genera. Degradation of anthocyanins was increased with drying temperature been Cy 3-glucosde and Cy 3-rutinoside the most abundant.

\section{1.- INTRODUCTION}

Berry fruits are a type of small fine fruits characterized by a red, purple and blue color. The most common are: blueberry, cranberry, blackberry, raspberry, white, red or blackcurrant and strawberry. The consumption of these fruits is mainly restricted to fresh product or processed food such as juice, beverage and jam due to their short shelflife, so thatdifferent marketing strategies like drying and/or packaging can be used to retain the quality of berries during storage ${ }^{1}$. In this sense, dried or frozen berries are the two most commonly consumed forms of these fruits despite the decrease in nutritional value found in the former or the high cost of transportation in the latter.

Berries contain high levels of polyphenols including flavonoids (anthocyanins, flavonols and flavanols such as condensed tannins or proanthocyanidins), hydrolysable tannins (ellagitannins and gallotannins), phenolic acids (hydroxybenzoic and hydroxycinnamic acids, chlorogenic acid), stilbenoids and lignans ${ }^{2,3}$. Many studies have been published in relation to the health benefits of berry consumption due to the presence of those active compounds ${ }^{4-6}$. Thanks to the rich and diverse composition of bioactive compounds and their health-promoting properties which result mostly from their antioxidant activity, their metal chelating capacity and their affinity for proteins, berry fruits are widely recognized as natural functional products ${ }^{7,8}$.

Since the availability of berries is seasonal, their processing for long-term storage and their addition to the formulation of new products are a good way to improve the nutritional quality of final products. The most commonly used methods of food preservation involve thermal treatments to reduce moisture content to a safe level, depriving ACS Paragon Plus Environment 
41 molds of favorable proliferative conditions ${ }^{9,10}$. In this sense, convective drying is always an alternative to extend shelf life and allow powders to be used as additives of other food matrixes, promoting the use of these types of highly nutritious fruits ${ }^{11,12}$.

It should be noted that quality characteristics of dehydrated fruits will be affected by drying conditions, in which phytochemicals like anthocyanins and phenolic compounds are highly susceptible to degradation ${ }^{13}$, thus reducing their antioxidant activity, and in general, their functional characteristics. Some studies related to drying berries indicate that this technological process may have negative effects on bioactive compounds compared to their fresh counterpart ${ }^{11}$. Therefore, the conditions of the drying process can produce light or moderate effects on fruit's bioactive compounds, mainly depending on the type of drying process and the fruit species ${ }^{14}$. As a result, dried fruits could not only be a good source of vitamins and fiber but also provide a wide array of bioactive phytochemicals that have been linked to a reduction in the risk of chronic diseases. Profiling the bioactive compounds that remains in dried fruits is the first step to address benefits associated to their consumption.

Since drying process affects appearance and chemical composition, the best method should be selected to ensure maximum conservation of bioactive compounds. Freeze drying is probably the best technique to reach high quality dried fruits; however, it is also one of the most expensive ones ${ }^{15}$. Moreover, freeze drying is the best method for obtaining a high-quality dried product (for heat sensitive materials) since it is commonly considered that minor modifications take place ${ }^{16}$. On the other hand, convective drying is the most economical and widely adopted technique in the food industry, despite requiring long drying times and high temperatures ${ }^{11}$. In the last years, new emerging technologies for drying fruits have been studied ${ }^{9}$, although due to fine fruits like berries are commonly more expensive than others, their applications increases the cost even more. This fact reinforces the study of traditional drying technologies in order to determine the best conditions to preserve the characteristics of dried fruits that could be used to food enrichment without considerable costs increase of final product. Additionally, the effects of drying on polyphenolics and antioxidant activities have not been systematically studied, this selecting the best conditions to maximize presentation of color, anthocyanins and antioxidant activity, is crucial to produce dried fruit powder to be used as food coloring, snack production or functional ingredients to be included in other food products. Therefore, the aim of this work was to study the impact of convective drying at different temperatures those characterizes of berry fruits and to chemically characterize their polyphenolic composition.

\section{2.- MATERIALS AND METHODS}


The berry fruits for the present research were selected from four species, each two belonging to a different genus. Raspberry (Rubus idaeus var. Autumn Bliss) and boysenberry (R. ursinus $\times$ R. idaeus var. Black Satin) were chosen from Rubus genus, and redcurrants (Ribes rubrum sp.) and blackcurrants (Ribes nigrum sp.) from Ribes genus. All berries were purchased from Dolphes Gourmet (Rosario, Argentina) as Individual Quick Frozen (IQF) fruits, assuring low-quality changes and longer conservation times. Rubus genus fruits came from San Pedro, Buenos Aires (Argentina) while Ribes genus fruits from El Bolsón, Río Negro (Argentina). Fruits from two different crop years were purchased and combined in two pools considered as duplicates (raspberry and boysenberry from 2014-2015 and redcurrants and blackcurrants from 2013-2014).

All chemicals were of analytical grade unless otherwise stated. Formic and clorhidric acids, methanol and acetonitrile (HPLC grade) were obtained from Fisher Scientific (Madrid, Spain). Delphinidin-3-glucoside, cyanidin-3-glucoside, peonidin-3-glucoside, pelargonidin-3-glucoside and malvidin-3-glucoside standards were purchased from Extrasynthese (Lyon, France).

\section{2.- Methods}

\subsection{1.- Physicochemical characteristics of selected berry fruits}

Water content (method 934.06), ash (method 930.35) and proteins (method 920.152) were determined according to AOAC methods ${ }^{17}$. It should be noted that fruits and their seeds were analyzed.

\subsection{2.- Berries drying}

Figure 1 shows the procedure used for drying berries. Briefly, each berry sample was separated in three sets in order to apply different convective drying conditions: $50{ }^{\circ} \mathrm{C}$ for $48 \mathrm{~h}, 65{ }^{\circ} \mathrm{C}$ for $20 \mathrm{~h}$ or $130{ }^{\circ} \mathrm{C}$ for $2 \mathrm{~h}$ until a moisture content below 15\% was obtained. Until that, berries were blanched for 3 min in a home steamer (Smart-Tek SD2071, Argentina) for better conservation of anthocyanins and polyphenols and inactivation of polyphenol oxidase from berries as reported by Sablani et al., ${ }^{15}$. The blanched fruits were carefully placed in a plastic mesh inside the air convection drier and separated in three portions and were exposed to the previously described conditions. Additionally, freeze-dried berries were obtained by storage at $-80{ }^{\circ} \mathrm{C}$ and freeze dried for $48 \mathrm{~h}$ (L-T8 RIFICOR, Argentina). These samples were used as a reference assuming no significant modifications induced by lyophilization method. All samples were ground in a coffee mill (PE-MC9100, Peabody, Argentina) and stored at $-18{ }^{\circ} \mathrm{C}$ prior to analysis. Water activity was measured by using an electric hygrometer Novasina Lab MASTER-aw (Novasina AG, 
97

98

Lanchen, Switzerland) at $25^{*} \mathrm{C}$. Measurements were done in duplicate and are expressed as the media +- standard deviation.

\subsection{3.- Color of dried berries}

The color of dried fruit powders was measured with a spectrophotometer (Minolta, Ramsey, NJ). Eight-millimeter measurement apertures, D65 illuminant, $10^{\circ}$ angle of observer was settled and color recorded in CIE Lab space. $\mathrm{L}^{*}$ indicates lightness, its value ranging from 0 (black) to 100 (white); $a^{*}$ and b* are the chromaticity coordinates. From the CIELAB coordinates, color function chroma $\left(\Delta \mathrm{C}_{\mathrm{ab}}\right)$ and total color change $(\Delta \mathrm{E})$ were calculated according to the following equations:

$$
\begin{array}{ll}
\Delta \mathrm{C}_{\mathrm{ab}}=\left(\Delta \mathrm{a}^{2}+\Delta \mathrm{b}^{* 2}\right)^{0.5} & \text { eq. } 1 \\
\Delta \mathrm{E}=\left(\Delta \mathrm{L}^{* 2}+\Delta \mathrm{a}^{2}+\Delta \mathrm{b}^{* 2}\right)^{0.5} & \text { eq. } 2
\end{array}
$$

\subsection{4.- Bioactive compounds and antioxidant activity in dried berries}

\subsubsection{1.- Anthocyanin analysis}

\subsubsection{1.- Anthocyanin profile by HPLC-DAD-ESI/MS-QTOF}

The analytical protocol for anthocyanins profile determination of the different samples studied is presented in Figure 2. Briefly, the method of anthocyanin purification was performed according to García-Herrera et al. ${ }^{18}$. A hydroalcoholic extraction was done and samples were purified by an aqueous extraction followed by a amethanolic one, both extracts were mixed and passed though Agilent Tech cartridge (Figure 2). This extract was used to obtain the anthocyanin profile by HPLC analysis carried out on a liquid chromatography system (Hewlett Packard Agilent 1200 Series) equipped with a quaternary pump and a photo- diode array detector (DAD) (Agilent Technologies). The column used was a Phenomenex Luna C18 column $(5 \mu \mathrm{m}, 4.6 \mathrm{~mm} \times 150 \mathrm{~mm})$, set thermostatically at $25{ }^{\circ} \mathrm{C}$. Chromatographic data were acquired and processed using an Agilent Chemstation for LC 3D system (Rev. B.04.01, Agilent Technologies). Briefly, the binary mobile phase used for analysis was aqueous $0.1 \%$ formic acid and HPLCgrade acetonitrile at a flow rate of $0.5 \mathrm{~mL} \mathrm{~min}$. Samples were analyzed in triplicate. Peaks were identified by comparing their retention time (Rt) and UV- visible spectra with the reference compounds, and the data were quantified using the corresponding curves of the reference compounds as standards, when available.

To confirm the identity of the compounds recorded, additional analyses were performed using HPLC coupled with mass spectrometry detection (HPLC-MS- QTOF): liquid chromatography/mass selective Agilent 1200: quaternary pump (G1311A), diode array detector (G1315B). The column used was an Phenomenex Luna C18 column (5 $\mu \mathrm{m}, 4.6$ 
126

127

128

129

130

131

132

133

134

135

136

137

138

139

140

141

142

143

144

145

146

147

Ionization (ESI) with JetStream technology; Instrument State: standard dynamic range $\mathrm{m} / \mathrm{z} 3200$. Software used was

Masshunter Data Acquisition B.04.00 and Masshunter Qualitative Analysis B.04.00.

2.2.4.1.2. Monomeric anthocyanin content

Four different solvent mixtures were prepared in order to extract the largest quantity of bioactive compounds from the whole fruits. Fifty milligrams of freeze-dried berries or $500 \mathrm{mg}$ of air-dried were mixed with $1.5 \mathrm{ml}$ of each solvent mixture: methanol: water (70:30), methanol: water (50:50), ethanol: water (70:30) and acetone: water (70:30) in all cases with a final concentration of $0.1 \% \mathrm{HCl}$. The solvent/berry mixtures were mixed for $10 \mathrm{~min}$ and then centrifuged at $12,000 \mathrm{~g}$ for $15 \mathrm{~min}$. The supernatant was recovered and seven more extractions were performed. All determinations were made in the supernatants recovered. The solvent with better extraction performance based on the total anthocyanin content method was acetone: water (70:30) (data not shown), thus selected to determine total polyphenol content and antioxidant activity analysis (Figure 2).

Total anthocyanin content was performed according to Giusti and Wrolstad (2001) in the acidified dried berry extracts using an extinction coefficient (B) of $26,900 \mathrm{I} \mathrm{cm}^{-1} \mathrm{mg}^{-1}$ and a molecular weight (MW) of $449.2 \mathrm{~g} / \mathrm{mol}$ of cyanidin 3-glucoside. Absorbance were measured at $520 \mathrm{~nm}\left(\mathrm{~A}^{520}\right)$ and $700 \mathrm{~nm}\left(\mathrm{~A}^{700}\right)$ and calculated as follows:

$$
\text { Cyanidin 3-glucoside } \mu \mathrm{g} / \mathrm{g} \text { dried fruit }=\left[\left(\left(\mathrm{A}^{520}-\mathrm{A}^{700}\right)_{\mathrm{pH} 1^{-}}-\left(\mathrm{A}^{520}-\mathrm{A}^{700}\right)_{\mathrm{pH} 4.5}\right) \times \mathrm{MW} \times \mathrm{F} \times \mathrm{Ve} \times 10^{5}\right] /(\mathrm{B} \times 1 \times \mathrm{Ws}) \text {, }
$$

F being the dilution factor for sample, Ve the extract volume and Ws the sample weight.

2.2.4.2.- Total polyphenol content

Total polyphenol content of dried berries was determined in two extracts as indicated in Figure 2, that was the methanolic extract made for anthocyanin profiling ) and in the acidified acetone extract for extraction of bioactive components previously described. Total polyphenols were determined using the Folin-Ciocalteu method, with gallic acid as a calibration standard ${ }^{20}$. The concentration of total polyphenols was expressed as mg gallic acid per gram of fruit powder.

\subsubsection{3.- Antioxidant activity determinations}

\subsubsection{1.- $\mathrm{ABTS}^{\circ+}$ radical cation scavenging activity}

$\mathrm{The}_{\mathrm{ABTS}}{ }^{\bullet+}$ radical cation scavenging activity was measured according to Re et al. ${ }^{21}$. Trolox (Sigma 238813) was used as a standard and results were expressed as $\mu \mathrm{mol}$ of Trolox equivalent per gram of fruit powder.

\subsubsection{3.- Ferric-reducing ability}

Ferric reducing activity of dried fruits was determined by FRAP assay according to Pulido et al., ${ }^{22}$ using gallic acid as a standard. 
All samples were prepared in duplicate and each replicate was quantified in duplicate. Results were analyzed by the adjustment to a model with fixed effects for a classification factor with eight levels (drying methods and fruit type).

The model included a variance function to take account of the presence of an increasing variability pattern related to medium levels of response variable. The adjustment was carried out using an implementation in InfoStat Software ${ }^{23}$ power variance varPower() from nlme library. This type of statistical analysis allows comparing, simultaneously, the effect of drying method and fruit type. Results of the analyses were evaluated by using DGC test ${ }^{26}$ with a degree of significance of $P<0.05$. Pearson correlation coefficients were used to determine the relationship between 166 anthocyanins contents determined by chromatographic and spectrophotometric methods.

\section{3.- RESULTS AND DISCUSSION}

\subsection{1.- Physicochemical characteristics of selected berry fruits}

167 The selected berry fruits were characterized according to their physicochemical composition as shown in Table 1. 168 The four berry fruits showed high water content, raspberry being the one with the highest value $(P<0.05)$. 169 Blackcurrant presented the highest ash content, almost twice that of the observed for raspberry and boysenberry. Protein content was significantly higher for raspberry compared with both currant and boysenberry. Carbohydrate content was twice higher for blackcurrant compared with raspberry, while boysenberry and redcurrant showed

172 intermediate values. USDA database ${ }^{27}$ was used as a reference for water content, protein and carbohydrate content of berries. Water content of selected berry fruits was very similar to the corresponding USDA value; yet, selected species showed increased protein content and slight difference in carbohydrate percentage compared to the 175 standard value.

Water activity is a factor that highly influence dried fruit stability. A high water activity can lead to a shorter storage time of products, which is due to the possibility of microbial growth and biochemical changes, has been suggested a value bellow 0.600 to eliminate these factors ${ }^{28}$. In this sense, the water activity of dried berries at different conditions ranged from 0.242 to 0.413 (Table 2). Considering each condition applied for drying fruits the final water activity decreased with increasing drying temperature, showing the following order: freeze-dried $(0.3269)>50{ }^{\circ} \mathrm{C}$ 
183

184

185

186

187

188

189

190

191

192

193

194

195

196

197

198

199

200

201

202

203

204

205

206

207

208

blackcurrant, similar values was found by Samoticha et al., ${ }^{29}$ after convective drying of chokeberries. As a result, it can be assumed that the obtained dried berries powders were microbiologically stable.

\subsection{2.- Color of dried berries}

Color and appearance in berries attract the consumer, they being associated with higher hedonic responses in fruits with darker color or higher anthocyanin content ${ }^{1,30}$. Additionally, changes in color during thermal processing of fruit might provide information about alterations in the content of anthocyanins and other polyphenols. Statistical analysis showed that not only fruit type determined color variables but also drying condition influences them with a significant interaction in luminosity $\left(\mathrm{L}^{*}\right)$, redness $\left(\mathrm{a}^{*}\right)$ and yellowness $\left(\mathrm{b}^{*}\right)$.

Luminosity of dried fruits decreased with increasing drying temperature in all fruits, raspberry samples being those with highest $L^{*}$ values in all cases. In addition, drying blackcurrants at all convective drying conditions generated a large decrease in $L^{*}$ with no significant difference $(p>0.05)$ between convective treatments (Figure 3$)$. As seen in Figure 3, in addition to the significant interaction between fruit species and drying conditions, freeze drying was the best option to obtain dried fruits with high luminosity ( $L^{*}=34.46$ on average), followed by drying at $65{ }^{\circ} \mathrm{C}\left(L^{*}=29.52\right.$ on average). On the other hand, convective drying at $130^{\circ} \mathrm{C}$ decreased largely luminosity with a mean value of 24.31 . From Figure 3 it is clear that redness was the most affected color parameter during convective drying of berries. In addition, slight differences were detected between fruit drying at $50^{\circ} \mathrm{C}$ or $65^{\circ} \mathrm{C}$ ( $a^{*}=7.38$ on average) compared to freeze-drying ( $a^{*}=25.62$ on average $)$ and high temperature drying ( $a^{*}=3.89$ on average). That means that the drying method showed a main effect on redness compared to fruit species. As observed with $L^{*}$ values, the highest redness was observed in freeze-dried berries. This could indicate that discoloration and browning during air drying may be the result of various chemical reactions including pigment destruction ${ }^{31}$.

Since selected fruits are red/purple, yellowness was the less affected color variable; only drying at $130{ }^{\circ} \mathrm{C}$ showed a clear effect with the lowest $b^{*}$ values $\left(b^{*}=1.81\right.$ on average). Raspberry presented the highest yellowness in all drying conditions (except for freeze-dried conditions), while blackcurrant showed the minimum yellowness in all conditions. For Rubus genus drying at $50{ }^{\circ} \mathrm{C}$ and $65{ }^{\circ} \mathrm{C}$ increased yellowness compared to freeze-dried conditions (Figure 3).

For better analysis of color modifications due to fruit species or drying conditions, chroma $\left(\Delta \mathrm{C}_{\mathrm{ab}}\right)$ and total color difference $(\Delta \mathrm{E})$ were determined (Table 3) using freeze-drying condition as a reference. Since chroma included variations in redness and yellowness, while total color difference also included luminosity, the similar values ACS Paragon Plus Environment 
observed in both parameters indicated that $L^{*}$ showed no considerable disparity between different dehydrated

fruits species. Boysenberry showed the minimum chrome and total color differences in all conditions followed by blackcurrant, indicating that blue fruits better conserved color parameters, while major changes were found for raspberry dried at $130^{\circ} \mathrm{C}$.

\subsection{3.- Bioactive compounds and antioxidant activity in dried berries}

\subsubsection{1.- Anthocyanin analysis}

Anthocyanin quantification was carried out using two methods: HPLC-DAD-ESI/MS-QTOF (anthocyanin profile) and a spectrophotometric estimation (monomeric anthocyanins expressed as $\mu \mathrm{g}$ cyanidin 3-glucoside). Anthocyanin profile profile showed that freeze-drying was the condition with the highest anthocyanin content in all samples. On the other hand, air-drying at $130{ }^{\circ} \mathrm{C}$ destroys anthocyanins, quantification in both purple fruits (boysenberry and blackcurrant) being minimum, in agreement with the low values in total color difference and chroma results described above.

Cy-3-sophoroside was co-eluted with Cy-3-sophoroside-5-rhamnoside in our conditions and thus quantified together. These two cyanidin compounds were the major anthocyanins in raspberry, reaching $52.3 \%$ of total anthocyanin in lyophilized form, in agreement with other authors ${ }^{32,18,33}$. Compared with freeze-drying, only $56 \%$ and $25 \%$ of those anthocyanins were conserved when drying at $50{ }^{\circ} \mathrm{C}$ and $65{ }^{\circ} \mathrm{C}$ was applied, respectively, while no anthocyanin was detected in raspberry dehydrated at $130^{\circ} \mathrm{C}$. A similar proportion of $\mathrm{Cy}$-3-glucoside conservation at intermediate drying temperatures was also detected for that fruit.

The anthocyanin profile of boysenberry was consistent with those of previously reports in blackberries ${ }^{33-35}$ with a single major peak representing $\mathrm{Cy}$-3-glucoside that constituted $88.8 \%$ of the total anthocyanin content in the freeze- 
240

241

242

243

244

245

246

247

$27 \%$ of $\mathrm{Cy}-3$-glucoside conserved, respectively. In addition, in samples dried at $130^{\circ} \mathrm{C}$, a minimum quantity of four anthocyanins was found.

Delphinin-3-rutinoside and Cy-3-xylosyl-rutinoside were present in redcurrant at all drying conditions (except for drying at $130^{\circ} \mathrm{C}$ ), Cy-3-xylosyl-rutinoside accounting for around $72.8 \%$ of total anthocyanins. As observed for boysenberry, drying at $50^{\circ} \mathrm{C}$ and $65^{\circ} \mathrm{C}$ produced the similar loss of compounds compared to freeze-dried redcurrant (Table 5). Blackcurrant showed equal quantity of rutinoside derivatives conserved after drying at $50^{\circ} \mathrm{C}$ compared to lyophilized form.

Although no anthocyanin was found in blackcurrant dehydrated at $65^{\circ} \mathrm{C}$ and a depreciable amount was found after drying at higher temperature, the profile observed in both Ribes genera was similar to those of other authors that reported delphinine-3-rutinose in both fruits with higher content in blackcurrant than in redcurrant ${ }^{32,33,36,37}$.

Figure 5 shows that results similar to the total anthocyanin detected by HPLC-DAD method were obtained when estimating the monomeric anthocyanin concentration via the spectrophotometric method with a Pearson's correlation coefficient of $0.76(P<0.05)$. In general, blackcurrant was the fruit with the highest anthocyanin content in all conditions (except drying at $65^{\circ} \mathrm{C}$ by HPLC-DAD method) followed by boysenberry, which could be attributed to the dark color of these berry species. Similar results were found by Arancibia-Avila, et al. ${ }^{13}$ by comparing raspberry and blueberries, indicating that color differences where closely associated to anthocyanins content. In this regard, raspberry and redcurrant showed the lowest anthocyanin content, showing similar values between them. With both drying methods a detrimental effect of drying conditions was observed, from which freeze-drying was found to be the method which allowed conservation of the highest concentration of anthocyanins. Drying berries at $50{ }^{\circ} \mathrm{C}$ or 65 ${ }^{\circ} \mathrm{C}$ produced fruits with similar anthocyanin content and the differences detected in freeze-dried berries according to each fruit was conserved but less pronounced. On the other hand, drying at $130{ }^{\circ} \mathrm{C}$ showed almost complete loss of anthocyanins (Figure 5).

In general, anthocyanin degradation seems to be more related to drying temperature than with exposure time since with increase in temperature, the time needed to dry fruits was reduced. As a result, anthocyanins were destroyed with increased drying temperature in a different proportion according to fruit species (significant interaction), in agreement with Karam et $a l,{ }^{11}$. Drying berries at intermediate temperatures produced fruit powders that conserved a considerable proportion of anthocyanins with a process much more economical than with freeze-drying.

Although it is well known that the spectrophotometric method is not specific, in the present work we have demonstrated that this method allowed assessing differences between drying conditions or fruit species in a quicker, ACS Paragon Plus Environment 
269 less time-consuming and simple way than with HPLC-DAD (Pearson coefficient $=0.97, P<0.0001$ ). This is important as 270 a first attempt for screening since identifying the anthocyanin compounds present or lost in each fruit or treatment 271 applied is still required to better understand results.

\section{$272 \quad$ 2.3.3.2.- Total polyphenol content}

273 Statistical analysis based on the mixed model proposed showed a significant berry species-dependent source 274 strength change pattern of total polyphenol and antioxidant activity in berries for all drying conditions applied.

275 Total polyphenol content (TPC) of dried berries was analyzed in two solvent mixtures as described in the materials 276 and methods section. Table 6 shows the results obtained and can be seen that contrary to that observed for 277 anthocyanin content, the drying processes increased or decreased TPC, being dependent on the fruit species and 278 conditions applied.

279 Total polyphenol content (TPC) in acidified acetone extract (AcE) of dried fruits was higher than in acidified 280 methanolic extracts (MeE) in almost all samples (Table 6). These could be ascribed to the fact that MeE extracts were 281 processed to reduce sugar and interferences in HPLC-DAD analysis, which are known that react with Folin-Ciocalteu 282 reagent ${ }^{38}$; Aqueous acetone has also been recognized as being more efficient in the extraction of condensed 283 polyphenols ${ }^{39}$.

Accordingly, TPC in MeE for all dried berries in all conditions was higher than the corresponding freeze-dried counterpart which could be explained by the reduction of interferences in these extracts, allowing the increase in polyphenols due to release of bounded compounds (Table 6). These phenomena have also been reported in grape pomace and seeds ${ }^{40}$, cranberry pomace $^{41}$ and hazel ${ }^{42}$.

Drying at $50{ }^{\circ} \mathrm{C}$ significantly decreased TPC in all fruits in ACE, in agreement with other studies reporting polyphenol freeze-dried samples, while the other berries lost around $70 \%$.

At $65^{\circ} \mathrm{C}$ TPC significantly increased in all berries species $(\mathrm{P}<0.05)$, particularly for Rubus genus in both extracts. This drying condition with higher air temperature and shorter drying times than lyophilized or $50{ }^{\circ} \mathrm{C}$ resulted in an increased content of compounds able to react with a Folin-Ciocalteu reagent, reducing substances and nitrogencontaining compounds formed during temperature-dependent processing ${ }^{38,43}$. Hence, the increase observed in TPC may probably be attributed to oxidation reactions of hydroxyl groups that produced more polyphenols or to 
such as $65{ }^{\circ} \mathrm{C}$ showed an almost complete conservation for Ribes or an increased polyphenol content for Rubus, indicating that phenolic compounds in berries varied in structure and stability associated with each genus selected. Berries dried at $130{ }^{\circ} \mathrm{C}$ showed that the increase in temperature was such that the degradation of polyphenols, interferences and Maillard products were also lost, resulting in an almost complete destruction of compounds capable of reacting with Folin-Ciocalteu reagent (4 to 17\% of retention). These changes may affect the reactivity of aromatic rings, which could explain the decrease in the polyphenol content measured in the presence of FolinCiocalteu reagent in AcE from berries dried at $130^{\circ} \mathrm{C}$.

It is remarkable that berries with blue color showed, in general, higher polyphenol content than the red ones in AcE it also holds true for MeE, with a few exceptions (Table 6).

Differences found in TPC extracts reflect that polyphenols isolated during anthocyanin extraction by SPS solid extraction of the MeE included no significant amount of compounds that allow analyzing the effect of drying conditions, probably due to treatment to reduce interferences which eliminates most of Maillard products; thus the results were more related to berry species.

As we have reported, the decrease in TPC observed at some drying conditions could be due to degradation of compounds, in which case a decrease in antioxidant activity is expected, even if it is well known that, for instance, Maillard reaction products have shown to have some antioxidant effect ${ }^{44}$. On the other hand, the increase in TPC observed in fruits dried at $65{ }^{\circ} \mathrm{C}$ could be attributed to release of bounded polyphenols, other than anthocyanins, so that an increase or conservation of antioxidant potential is expected. As a result, the $\mathrm{ABTS}^{\circ+}$ radical cation scavenging activity and ferric-reducing power of AcE extracts were tested. We decided to use AcE extracts over MeE since that extraction was not purified, giving a more real measure of total antioxidant potential, even when it could be related, in part, to Maillard compounds, as reported by ${ }^{14}$.

\subsubsection{3.- Antioxidant activity determinations}

Many matrixes have been tested to study the effect of drying on antioxidant activity ${ }^{13,15,45}$. Although the most important mechanism of antioxidant potential in berries is antiradical activity, in the present research the ferricreducing power was also analyzed to further study the effect of different drying temperatures in both activities.

Freeze-dried berries showed very similar $\mathrm{ABTS}^{\circ+}$ radical cation scavenging activity, purple fruits (boysenberry and blackcurrant) being the ones with the highest content $(P<0.05)$ (Figure 6), although lyophilized fruits showed that blackcurrant was the berry with the highest reducing power, followed by boysenberry and redcurrant with very similar content between both, and raspberry with the lowest value. Convective drying of berries from Ribes genus 
produced the almost complete loss of antioxidant activity considering both mechanisms: radical scavenging activity and reducing power with slight differences between them as previously described by other authors ${ }^{14,15,31}$. In addition, $\mathrm{ABTS}^{\circ+}$ radical cation scavenging activity of Rubus fruits was maximum in all drying conditions tested. Convective drying at $50{ }^{\circ} \mathrm{C}$ produced slight loss of radical scavenging activity in Rubus genus, although this effect was not observed in the ferric-reducing power assay (Figure 6).

The increase of $\mathrm{ABTS}^{\circ+}$ radical cation scavenging activity in berries from Rubus genus was also observed for ferric reducing power in fruits dried at $65{ }^{\circ} \mathrm{C}$. This observation agrees with the increase in polyphenol content observed after drying berry samples at $65^{\circ} \mathrm{C}$, which could be probably due to the depolymerization which increases free polyphenols. Additionally, polyphenols may be degraded during long-time drying (like the one performed at $50^{\circ} \mathrm{C}$ ) or by the use of high temperature $\left(130^{\circ} \mathrm{C}\right)$; as a result, both activities were highly affected (Figure 6), particularly in Ribes genus. This means that the best convective drying condition to produce dried Rubus berries has shown to be the one at $65^{\circ} \mathrm{C}$ for $20 \mathrm{~h}$, while no significant difference was found between drying Ribes fruits at $50{ }^{\circ} \mathrm{C}$ or $65^{\circ} \mathrm{C}$ (except for BC).

$\mathrm{ABTS}^{\circ+}$ radical cation scavenging activity and ferric-reducing power showed significant correlation coefficients with total polyphenol content: 0.65 and 0.82 , respectively $(P<0.05)$. Additionally, significant correlation coefficients were observed between total anthocyanin and antiradical activity $(0.40, \mathrm{P}=0.0012)$ and with ferric-reducing power $(0.71$, $\mathrm{P}<0.0001)$

343 In conclusion, anthocyanin profiles of selected berries showed high predominance of delphinidin and cyanidin derivatives. Particularly, cyanidin 3-sophoroside derivatives and cyanidin 3-glucoside in Rubus genus and delphinidin 3-rutinoside and cyanidin-3-rutinoside in Ribes genus. As far as we know, there is scarce information available on the anthocyanin profile of these particular species, specifically from blackberry hydride, which constitutes a valuable contribution.

The study of the degradation of bioactive compounds in dried fruits is complex and dependent on the conditions used during drying. Better understanding of the best method of fruits drying for better preservation of bioactive compounds is required not only to avoid their loss during processing and storage of food, but also to determine possible implications to human health. In addition, the use of a simple and low-cost drying method such as a convective drying is a good alternative to include the dried product in other food matrixes without considerable 
355

356

357

358

359

360

361

362

363

on the particular red fruit. In particular, drying berries at $65^{\circ} \mathrm{C}$ during $20 \mathrm{~h}$ was the best choice for the conservation of color, polyphenol content and antioxidant activity while anthocyanin content was similar in berries dried at $50{ }^{\circ} \mathrm{C}$ or $65^{\circ} \mathrm{C}$. It is clear that drying at temperature above $100{ }^{\circ} \mathrm{C}$ greatly deteriorates all the berry properties analyzed. It is remarkable that berries dried at $65{ }^{\circ} \mathrm{C}$ could be a great option to produce berry powder in order to improve the nutritional and sensorial characteristics of the final products. Conventional drying is a much more economical drying method than lyophilizationand shows a considerable increase of total polyphenol content due to depolymerization of native polyohenols that also leads to increased antioxidant activity with pleasant smell and color.

\section{REFERENCES}

(1) Laaksonen, O.; Knaapila, A.; Niva, T.; Deegan, K. C.; Sandell, M. Sensory Properties and Consumer Characteristics Contributing to Liking of Berries. Food Qual. Prefer. 2016, 53, 117-126.

(2) Saavedra, M.; Borges, A.; Dias, C.; Aires, A.; Bennett, R.; Rosa, E.; Simões, M. Antimicrobial Activity of Phenolics and Glucosinolate Hydrolysis Products and Their Synergy with Streptomycin against Pathogenic Bacteria. Med. Chem. (Los. Angeles). 2010, 6 (3), 174-183.

(3) Bowen-Forbes, C. S.; Zhang, Y.; Nair, M. G. Anthocyanin Content, Antioxidant, Anti-Inflammatory and Anticancer Properties of Blackberry and Raspberry Fruits. J. Food Compos. Anal. 2010, 23 (6), 554-560.

(4) Battino, M.; Beekwilder, J.; Denoyes-Rothan, B.; Laimer, M.; McDougall, G. J.; Mezzetti, B. Bioactive Compounds in Berries Relevant to Human Health. Nutr. Rev. 2009, 67 (Suppl 1), S145-S150.

(5) Yang, B.; Kortesniemi, M. Clinical Evidence on Potential Health Benefits of Berries. Curr. Opin. Food Sci. 2015, 2, 36-42.

(6) Vendrame, S.; Del Bo', C.; Ciappellano, S.; Riso, P.; Klimis-Zacas, D. Berry Fruit Consumption and Metabolic Syndrome. Antioxidants 2016, 5 (4), 34.

(7) Szajdek, A.; Borowska, E. J. Bioactive Compounds and Health-Promoting Properties of Berry Fruits: A Review. Plant Foods Hum. Nutr. 2008, 63 (4), 147-156.

(8) Keast, D. R.; O’Neil, C. E.; Jones, J. M. Dried Fruit Consumption Is Associated with Improved Diet Quality and Reduced Obesity in US Adults: National Health and Nutrition Examination Survey, 1999-2004. Nutr. Res. 2011, $31(6), 460-467$.

(9) Sousa-Gallagher, M. J.; Tank, A.; Sousa, R. Emerging Technologies to Extend the Shelf Life and Stability of Fruits and Vegetables. In The Stability and Shelf Life of Food; Subramaniam, P., Ed.; Elsevier: USA, 2016; pp 399-430. 
384

385

386

387

(10) Rawson, A.; Patras, A.; Tiwari, B. K.; Noci, F.; Koutchma, T.; Brunton, N. Effect of Thermal and Non Thermal Processing Technologies on the Bioactive Content of Exotic Fruits and Their Products: Review of Recent Advances. Food Res. Int. 2011, 44 (7), 1875-1887.

(11) Karam, M. C.; Petit, J.; Zimmer, D.; Baudelaire Djantou, E.; Scher, J. Effects of Drying and Grinding in Production of Fruit and Vegetable Powders: A Review. J. Food Eng. 2016, 188, 32-49.

(12) Bennett, L. E.; Jegasothy, H.; Konczak, I.; Frank, D.; Sudharmarajan, S.; Clingeleffer, P. R. Total Polyphenolics and Anti-Oxidant Properties of Selected Dried Fruits and Relationships to Drying Conditions. J. Funct. Foods 2011, 3 (2), 115-124.

(13) Arancibia-avila, P.; Namiesnik, J.; Toledo, F.; Werner, E.; Martinez-Ayala, A. L.; Rocha-Guzmán, N. E.; GallegosInfante, J. A.; Gorinstein, S. The Influence of Different Time Durations of Thermal Processing on Berries Quality. Food Control 2012, 26 (2), 587-593.

(14) Omolola, A. O.; Jideani, A. I. O.; Kapila, P. F. Quality Properties of Fruits as Affected by Drying Operation. Crit. Rev. Food Sci. Nutr. 2015, 57, 95-108.

(15) Sablani, S. S.; Andrews, P. K.; Davies, N. M.; Walters, T.; Saez, H.; Bastarrachea, L. Effects of Air and Freeze Drying on Phytochemical Content of Conventional and Organic Berries. Dry. Technol. 2011, 29 (2), $205-216$.

(16) Marques, L. G.; Silveira, A. M.; Freire, J. T. Freeze-Drying Characteristics of Tropical Fruits. Dry. Technol. 2006, $24(4), 457-463$.

(17) AOAC. Official Methods of Analysis, 18th ed.; Horwitz, W., Latimer, G., Eds.; Association of Official Analytical Chemist: EUA, 2005.

(18) Garcia-herrera, P.; Pérez-Rodríguez, M.-L.; Aguilera-Delgado, T.; Labari-Reyes, M.-J.; Olmedilla-Alonso, B.; Camara, M.; de Pascual-Teresa, S. Anthocyanin Profile of Red Fruits and Black Carrot Juices, Purees and Concentrates by HPLC-DAD-ESI/MS-QTOF. Int. J. Food Sci. Technol. 2016, 51 (10), 2290-2300.

(19) Giusti, M. M. M.; Wrolstad, R. E. Characterization and Measurement of Anthocyanins by UV-Visible Spectroscopy. In Current Protocols in Food Analytical Chemistry; John Wiley \& Sons, Inc.: Hoboken, NJ, USA, 2001; Vol. 5, pp 1-13.

(20) Prior, R. L.; Wu, X.; Schaich, K. Standardized Methods for the Determination of Antioxidant Capacity and Phenolics in Foods and Dietary Supplements. J. Agric. Food Chem. 2005, 53 (10), 4290-4302.

(21) Re, R.; Pellegrini, N.; Proteggente, A.; Pannala, A.; Yang, M.; Rice-Evans, C. Antioxidant Activity Applying an Improved ABTS Radical Cation Decolorization Assay. Free Radic. Biol. Med. 1999, 26 (9-10), 1231-1237. 
413

414

415

416

417

(22) Pulido, R.; Bravo, L.; Saura-Calixto, F. Antioxidant Activity of Dietary Polyphenols As Determined by a Modified Ferric Reducing/Antioxidant Power Assay. J. Agric. Food Chem. 2000, 48 (8), 3396-3402.

(23) Di Rienzo, J.; Casanoves, F.; Balzarini, M. G.; Gonzalez, L.; Tablada, M.; Robledo, C. W. Infostat. Grupo InfoStat, FCA, Universidad Nacional de Córdoba, Argentina. 2012.

(24) Pinheiro, J.; Bates, D.; DebRoy, S.; Sarkar, D. Nlme: Linear and Nonlinear Mixed Effects Models. The R Development Core Team 2012.

(25) R Core Team. R: A Language and Environment for Statistical Computing. R Foundation for Statistical Computing: Vienna, Austria 2012.

(26) Di Rienzo, J.; Guzmán, A.; Casanoves, F. A Multiple-Comparisons Method Based on the Distribution of the Root Node Distance of a Binary Tree. J. Agric. Food Chem. 2002, 7 (2), 129-142.

(27) USDA. Standard values to be use as reference https://ndb.nal.usda.gov/ndb/search/list?SYNCHRONIZER_TOKEN=544f00e8-7f3d-4bf7-ad265ffd5e8cc63f\&SYNCHRONIZER_URI=\%2Fndb\%2Fsearch\%2Flist\&qt=\&ds=Standard+Reference\&qlookup=\&ma nu (accessed Aug 1, 2017).

(28) Jay, J. M.; Loessner, M. J.; Golden, D. A. Protection of Foods by Drying. In Modern food microbiology; Jay, J., Loessner, M., Golden, D., Eds.; Springer Science+Business Media: New York, 2005; pp 443-456.

(29) Samoticha, J.; Wojdyło, A.; Lech, K. The Influence of Different the Drying Methods on Chemical Composition and Antioxidant Activity in Chokeberries. LWT - Food Sci. Technol. 2016, 66, 484-489.

(30) Barrett, D. M.; Beaulieu, J. C.; Shewfelt, R. Color, Flavor, Texture, and Nutritional Quality of Fresh-Cut Fruits and Vegetables: Desirable Levels, Instrumental and Sensory Measurement, and the Effects of Processing. Crit. Rev. Food Sci. Nutr. 2010, 50 (5), 369-389.

(31) Sablani, S. S.; Andrews, P. K.; Davies, N. M.; Walters, T.; Saez, H.; Syamaladevi, R. M.; Mohekar, P. R. Effect of Thermal Treatments on Phytochemicals in Conventionally and Organically Grown Berries. J. Sci. Food Agric. 2010, 90, n/a-n/a.

(32) Borges, G.; Degeneve, A.; Mullen, W.; Crozier, A. Identification of Flavonoid and Phenolic Antioxidants in Black Currants, Blueberries, Raspberries, Red Currants, and Cranberries. J. Agric. Food Chem. 2010, 58 (7), 39013909.

(33) Patras, A.; Brunton, N. P.; O’Donnell, C.; Tiwari, B. K. Effect of Thermal Processing on Anthocyanin Stability in Foods; Mechanisms and Kinetics of Degradation. Trends Food Sci. Technol. 2010, 21 (1), 3-11. 
442

443

444

445

446

447

448

449

450

451

452

453

454

455

456

457

458

459

460

461

462

463

464

465

466

467

(34) Fan-Chiang, H. J.; Wrolstad, R. E. Anthocyanin Pigment Composition of Blackberries. J. Food Sci. 2005, 70 (3), $198-202$.

(35) Siriwoharn, T.; Wrolstad, R. E.; Finn, C. E.; Pereira, C. B. Influence of Cultivar, Maturity, and Sampling on Blackberry (Rubus L. Hybrids) Anthocyanins, Polyphenolics, and Antioxidant Properties. J. Agric. Food Chem. 2004, 52 (26), 8021-8030.

(36) Nour, V.; Stampar, F.; Veberic, R.; Jakopic, J. Anthocyanins Profile, Total Phenolics and Antioxidant Activity of Black Currant Ethanolic Extracts as Influenced by Genotype and Ethanol Concentration. Food Chem. 2013, $141,961-966$.

(37) Ruiz, A.; Hermosín-Gutiérrez, I.; Vergara, C.; von Baer, D.; Zapata, M.; Hitschfeld, A.; Obando, L.; Mardones, C. Anthocyanin Profiles in South Patagonian Wild Berries by HPLC-DAD-ESI-MS/MS. Food Res. Int. 2013, 51 (2), $706-713$.

(38) Escarpa, A.; González, M. . C. Approach to the Content of Total Extractable Phenolic Compounds from Different Food Samples by Comparison of Chromatographic and Spectrophotometric Methods. Anal. Chim. Acta 2001, $427(1), 119-127$.

(39) Yu, Z.; Dahlgren, R. A. Evaluation of Methods for Measuring Polyphenols in Conifer Foliage. J. Chem. Ecol. 2000, 26 (9), 2119-2140.

(40) Chamorro, S.; Goñi, I.; Viveros, A.; Hervert-Hernández, D.; Brenes, A. Changes in Polyphenolic Content and Antioxidant Activity after Thermal Treatments of Grape Seed Extract and Grape Pomace. Eur. Food Res. Technol. 2012, 234 (1), 147-155.

(41) White, B. L.; Howard, L. R.; Prior, R. L. Release of Bound Procyanidins from Cranberry Pomace by Alkaline Hydrolysis. J. Agric. Food Chem. 2010, 58 (13), 7572-7579.

(42) González, M. J.; Torres, J. L. L.; Medina, I.; Gonz??lez, M. J.; Torres, J. L. L.; Medina, I. Impact of Thermal Processing on the Activity of Gallotannins and Condensed Tannins from Hamamelis Virginiana Used as Functional Ingredients in Seafood. J. Agric. Food Chem. 2010, 58 (7), 4274-4283.

(43) Michalska, A.; Honke, J.; Łysiak, G.; Andlauer, W. Effect of Drying Parameters on the Formation of Early and Intermediate Stage Products of the Maillard Reaction in Different Plum (Prunus Domestica L.) Cultivars. LWT Food Sci. Technol. 2016, 65, 932-938.

(44) Yilmaz, Y.; Toledo, R. Antioxidant Activity of Water-Soluble Maillard Reaction Products. Food Chem. 2005, 93 (2), 273-278. 
471 (45) Vinson, J. A.; Zubik, L.; Bose, P.; Samman, N.; Proch, J. Dried Fruits: Excellent in Vitro and in Vivo Antioxidants.

472 J. Am. Coll. Nutr. 2005, $24(1), 44-50$.

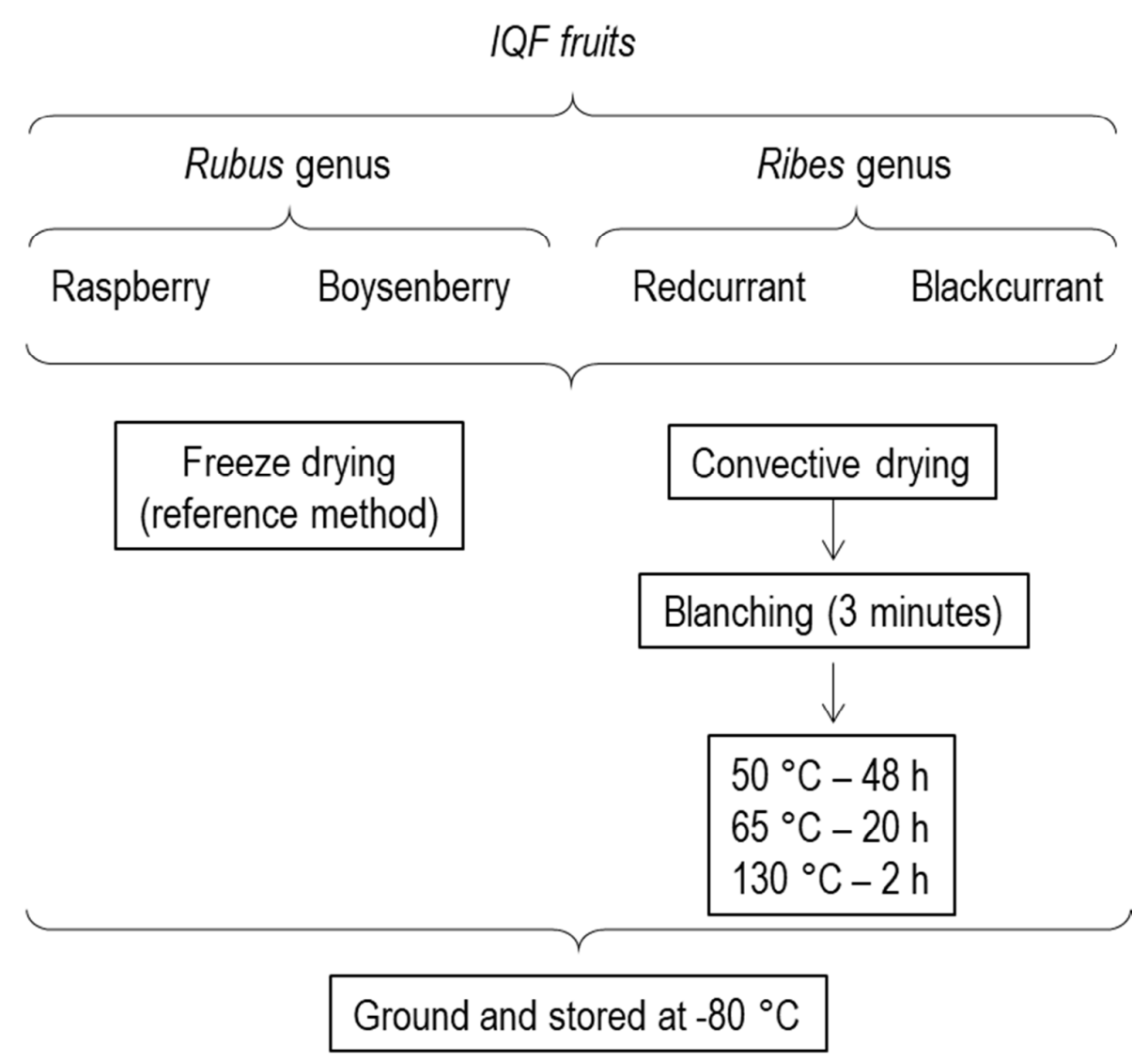

Figure 1.- Berries drying procedure. 


\section{Dried berries powder}

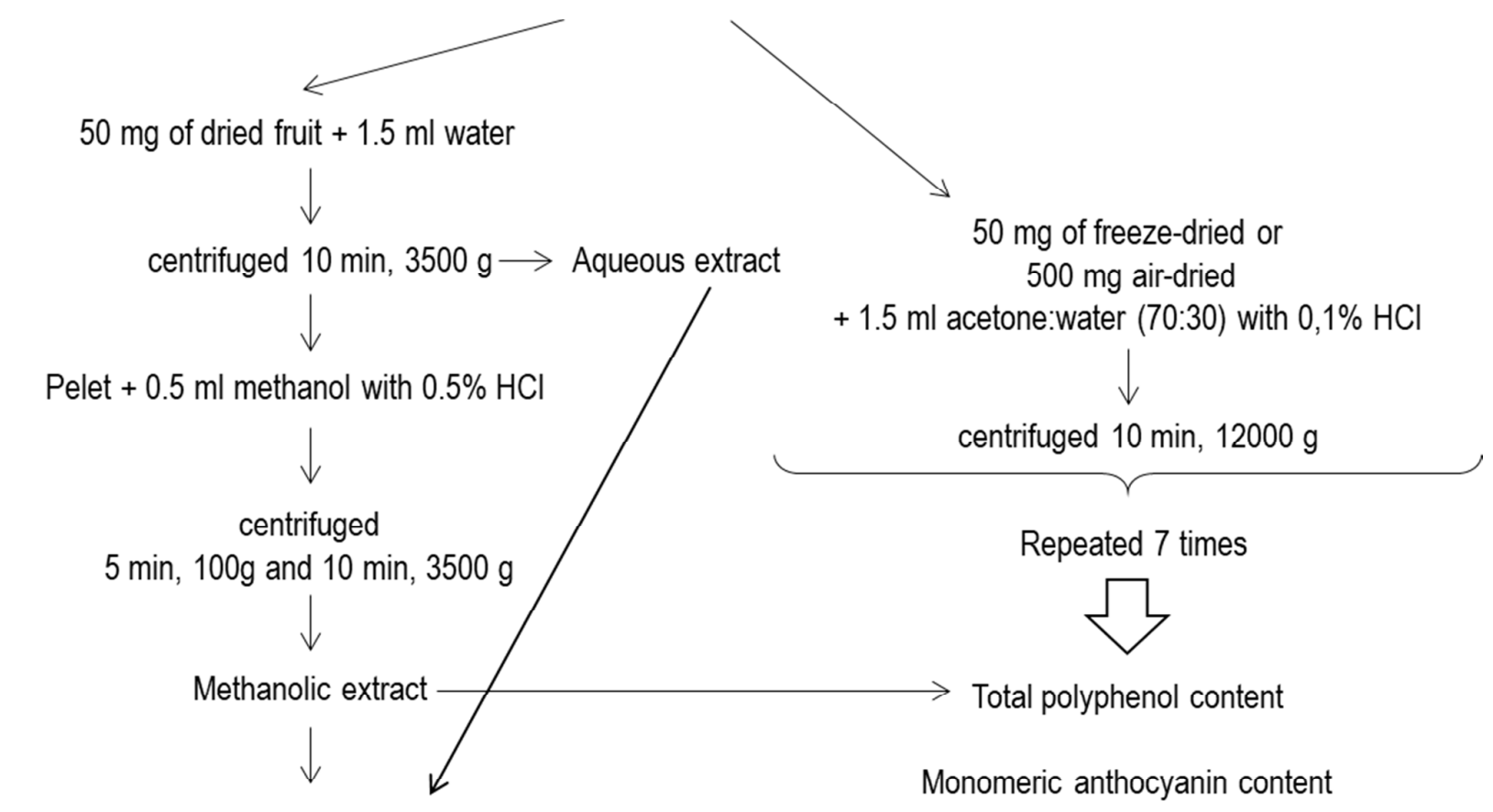

Vacuum evaporated mixed with aqueous extract and completed to $1.5 \mathrm{ml}$ with water

Radical cation ABTS scavenging activity

Ferric reducing ability

Filtrated in Agilent Tech cartridge and eluted with $1.5 \mathrm{ml}$

methanol acidified with $0.1 \% \mathrm{HCl}$.

Vacuum evaporated $+1 \mathrm{ml}$ folic acid $0.1 \%$

and filtrated to membrane $0,45 \mu \mathrm{m}$

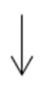

Anthocyanin profile

HPLC-DAD-ESI/MS-QTOF

Figure 2.- Analytical protocol for anthocyanin profiling, total polyphenol content and antioxidant activity determinations. 


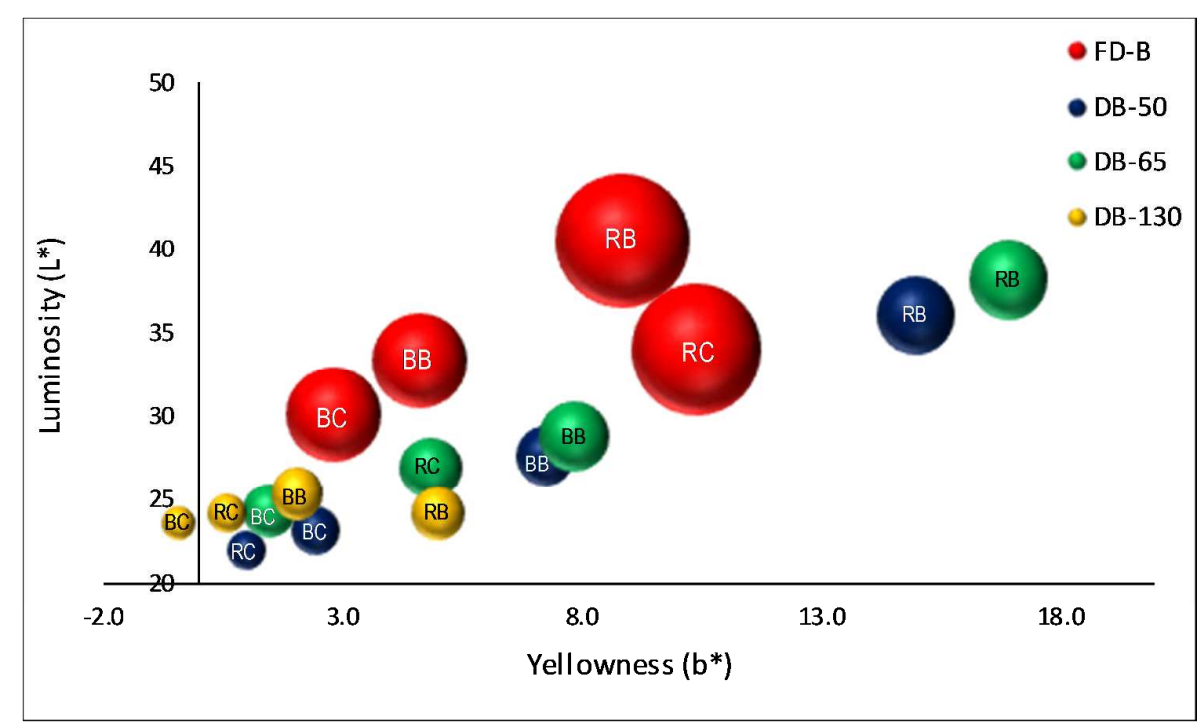

Figure 3.- Color parameters of dried berries at different conditions. Bubbles sized are related to redness (a*) value. Raspberry (RB), boysenberry (BB), redcurrant (RC) and blackcurrant (BC). 

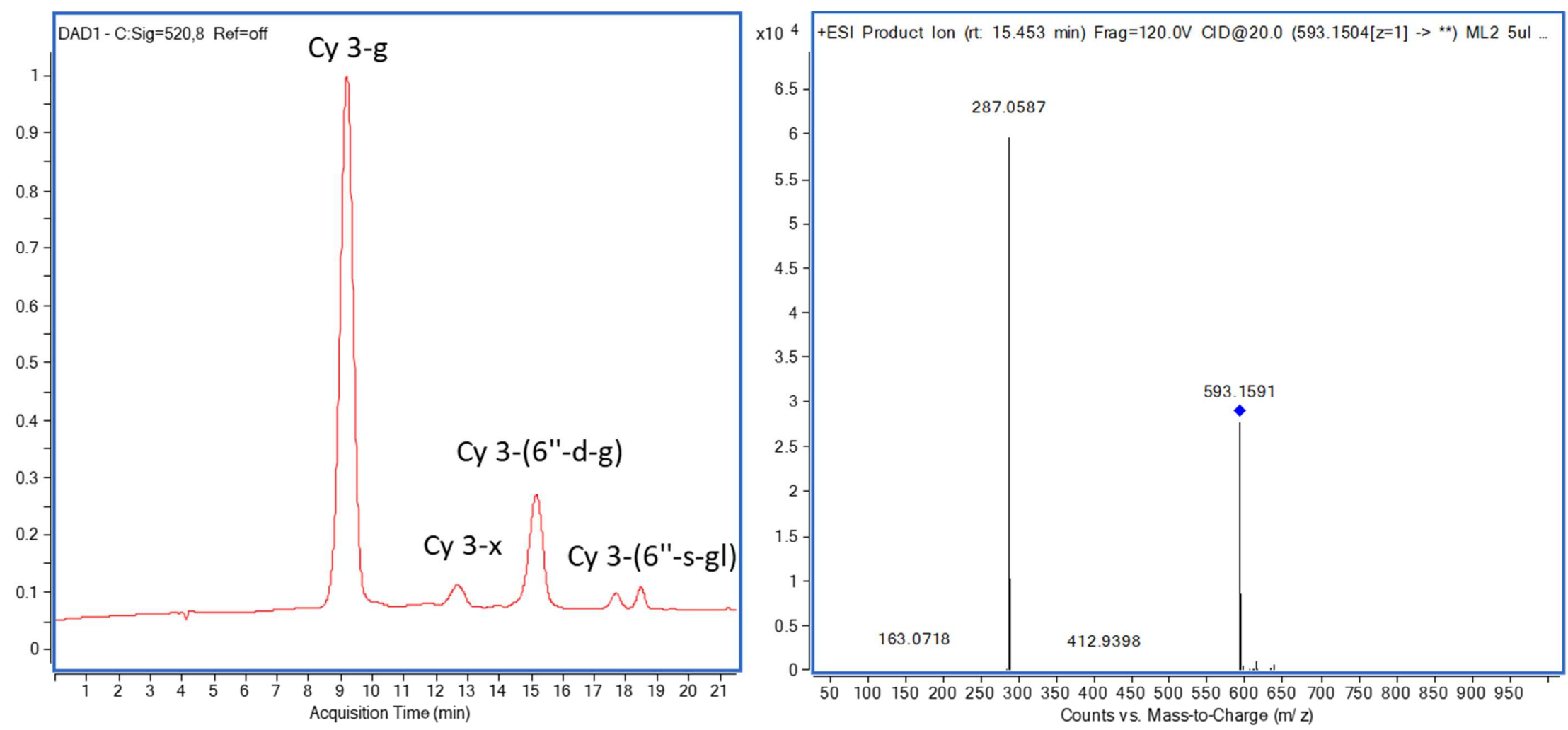

Figure 4.- Chromatogram at $520 \mathrm{~nm}$ corresponding to sample boysenberry (BB) lyophilized (left) and MSMS spectra of the peak eluting at 15.3 min with a M+ of 593.16 that has been identified as Cyanidin 3-(6"-dioxalyl-glucoside) (right). Cy 3-g, Cyanidin 3-glucoside; Cy 3-x, Cyanidin 3-xyloside; Cy 3-(6"-d-g), Cyanidin 3-(6"-dioxalyl-glucoside) 


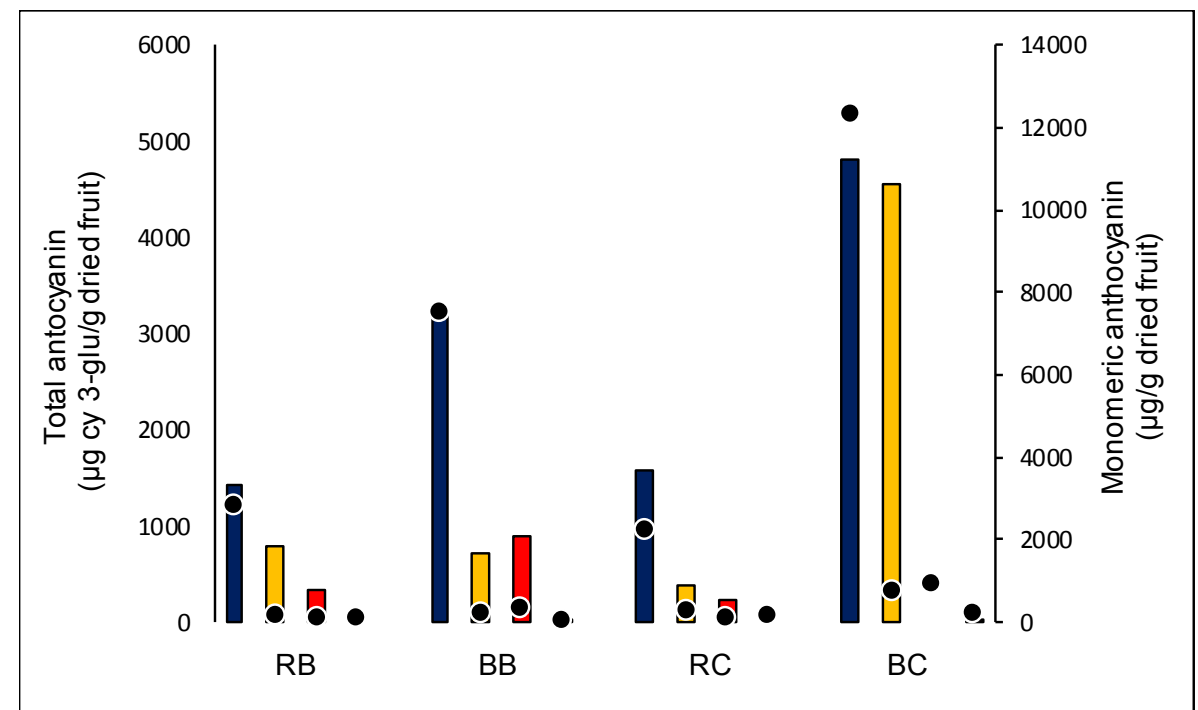

Figure 5.- Total anthocyanin by HPLC-DAD (bars) and monomeric anthocyanin (dots) of freeze-dried berries (blue) and berries dried at $50^{\circ} \mathrm{C}$ (yellow), $65^{\circ} \mathrm{C}$ (red) and $130{ }^{\circ} \mathrm{C}$ (green).

Raspberry (RB), boysenberry (BB), redcurrant (RC) and blackcurrant (BC). *logarithmic scale 


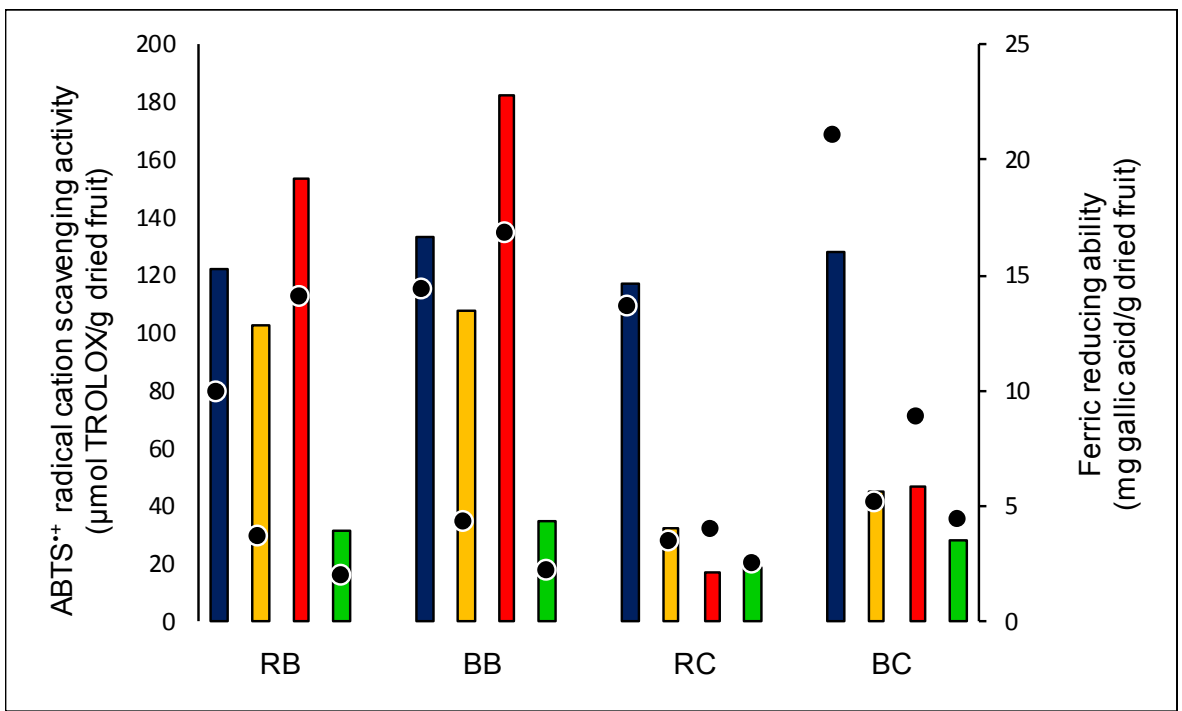

Figure 6.- $\mathrm{ABTS}^{\circ+}$ radical cation scavenging activity (bars) and ferric-reducing power (dots) of freeze-dried berries (blue) and berries dried at $50{ }^{\circ} \mathrm{C}$ (yellow), $65^{\circ} \mathrm{C}$ (red) and $130{ }^{\circ} \mathrm{C}$ (green). Raspberry (RB), boysenberry (BB), redcurrant (RC) and blackcurrant (BC). 
Table 1.- Physicochemical composition of selected berries*

\begin{tabular}{|c|c|c|c|c|}
\hline & Water content & Ash & Protein & Carbohydrate \\
\hline Raspberry & $85.8 \pm 0.4^{c}$ & $1.68 \pm 0.03^{a}$ & $4.7 \pm 0.1^{d}$ & $7.9 \pm 0.5^{a}$ \\
\hline USDA database $*^{1}$ & 85.75 & - & 1.20 & 11.94 \\
\hline Boysenberry & $83.0 \pm 0.4^{b}$ & $1.64 \pm 0.02^{a}$ & $3.6 \pm 0.0^{c}$ & $11.7 \pm 0.4^{b}$ \\
\hline USDA database $*^{1}$ & 88.15 & - & 1.39 & 9.61 \\
\hline Redcurrant & $82.4 \pm 0.8^{b}$ & $2.06 \pm 0.04^{b}$ & $2.8 \pm 0.0^{\mathrm{a}}$ & $12.8 \pm 0.7^{b}$ \\
\hline USDA database $*^{1}$ & 83.95 & - & 1.40 & 13.80 \\
\hline Blackcurrant & $75.4 \pm 0.3^{a}$ & $2.93 \pm 0.02^{c}$ & $3.1 \pm 0.2^{b}$ & $18.6 \pm 0.1^{c}$ \\
\hline USDA database ${ }^{*^{1}}$ & 81.96 & - & 1.40 & 15.38 \\
\hline
\end{tabular}

*Within the same column, values with different letters indicate significant differences $(\mathrm{P}<0.05) . *^{1}$

USDA standard value for reference: https://ndb.nal.usda.gov/ndb/search/list 
Table 2.- Water activity of dehydrated fruits*

\begin{tabular}{lcccc}
\hline Condition/Fruit & Raspberry & Boysenberry & Redcurrant & Blackberry \\
\hline Freeze-dried & $0.376 \pm 0.002^{\mathrm{d}}$ & $0.357 \pm 0.001^{\mathrm{c}}$ & $0.242 \pm 0.000^{\mathrm{a}}$ & $0.334 \pm 0.001^{\mathrm{b}}$ \\
$50{ }^{\circ} \mathrm{C}$ & $0.310 \pm 0.002^{\mathrm{c}}$ & $0.413 \pm 0.002^{\mathrm{d}}$ & $0.411 \pm 0.002^{\mathrm{d}}$ & $0.398 \pm 0.002^{\mathrm{d}}$ \\
$65^{\circ} \mathrm{C}$ & $0.251 \pm 0.001^{\mathrm{a}}$ & $0.326 \pm 0.001^{\mathrm{b}}$ & $0.342 \pm 0.003^{\mathrm{c}}$ & $0.343 \pm 0.002^{\mathrm{c}}$ \\
$130{ }^{\circ} \mathrm{C}$ & $0.302 \pm 0.001^{\mathrm{b}}$ & $0.280 \pm 0.001^{\mathrm{a}}$ & $0.291 \pm 0.001^{\mathrm{b}}$ & $0.282 \pm 0.001^{\mathrm{a}}$ \\
& & & & \\
\hline
\end{tabular}


Table 3.- Chroma $\left(\Delta C_{a b}\right)$ and total color difference $(\Delta E)$ for fruits dehydrated by convective drying*

\begin{tabular}{|c|c|c|c|c|c|c|c|c|c|c|c|c|}
\hline \multirow{2}{*}{$\begin{array}{l}\text { Air-drying temperature } \\
\text { Fruit sample }\end{array}$} & \multicolumn{4}{|c|}{$50^{\circ} \mathrm{C}$} & \multicolumn{4}{|c|}{$65^{\circ} \mathrm{C}$} & \multicolumn{4}{|c|}{$130^{\circ} \mathrm{C}$} \\
\hline & RB & BB & $\mathrm{RC}$ & $B C$ & RB & BB & $\mathrm{RC}$ & $B C$ & $\mathrm{RB}$ & BB & $\mathrm{RC}$ & $B C$ \\
\hline$\Delta \mathrm{C}_{\mathrm{ab}}$ & $24.3^{\mathrm{e}}$ & $10.7^{b}$ & $31.6^{h}$ & $13.0^{c}$ & $24.5^{b}$ & $8.3^{\mathrm{a}}$ & $26.3^{f}$ & $12.4^{c}$ & $29.9^{g}$ & $12.1^{\mathrm{c}}$ & $31.7^{h}$ & $15.7^{d}$ \\
\hline$\Delta \mathrm{E}$ & $24.8^{\mathrm{e}}$ & $12.2^{b}$ & $33.8^{g}$ & $14.8^{c}$ & $24.6^{\mathrm{e}}$ & $9.5^{a}$ & $27.2^{f}$ & $13.7^{c}$ & $34.1^{\mathrm{g}}$ & $14.5^{c}$ & $33.1^{\mathrm{g}}$ & $17.0^{d}$ \\
\hline
\end{tabular}

*Within the same row, values with different letters indicate significant differences $(P<0.05)$.

Raspberry (RB), boysenberry (BB), redcurrant (RC) and blackcurrant (BC). 
Table 4.- Anthocyanin profile in lyophilized berries.

\begin{tabular}{|c|c|c|c|c|c|}
\hline Peak (n) & $\operatorname{Rt}(\min )$ & Structure & $M+$ & $\begin{array}{c}\text { Fragments } \\
\text { MS-MS }\end{array}$ & fruit \\
\hline 1 & 7.7 & Cyanidin-3-sophoroside & 611.16 & $449.09,287.05$ & RB \\
\hline 2 & 7.7 & Delphinidin 3-rutinoside & 611.16 & $465.09,303.04$ & $\mathrm{BC}$ \\
\hline 3 & 8.3 & Cyanidin 3-sophoroside-5-rhamnoside & 757.21 & $433.1,287.05$ & RB \\
\hline 4 & 9.2 & Cyanidin 3-glucoside & 449.11 & 287.05 & $\mathrm{RB}, \mathrm{BB}$ \\
\hline 5 & 9.2 & Cyanidin 3-xylosyl-rutinoside & 727.2 & 287.06 & $\mathrm{RC}$ \\
\hline 6 & 9.7 & Cyanidin 3 -rutinoside & 595.16 & $449.1,287.05$ & $\mathrm{RC}, \mathrm{BC}$ \\
\hline 7 & 12.8 & Cyanidin 3-xyloside & 419.05 & 287.05 & BB \\
\hline 8 & 15.3 & Cyanidin 3-(6"-dioxalyl-glucoside) & 593.16 & 287.05 & BB \\
\hline 9 & 18.4 & Cyanidin 3-(6"-succinyl-glucoside) & 549.12 & 287.05 & BB \\
\hline
\end{tabular}

Raspberry (RB), boysenberry (BB), redcurrant (RC) and blackcurrant $(\mathrm{BC})$. 
Table 5.- Quantification of anthocyanins in dried fine fruits.

\begin{tabular}{|c|c|c|c|c|c|c|c|c|c|}
\hline $\begin{array}{c}\text { Drying } \\
\text { conditions }\end{array}$ & Fruit & $\begin{array}{c}\text { Cy 3- sophoroside + } \\
\text { Cy 3-sophoroside } \\
\text { 5-rhamnoside }\end{array}$ & $\begin{array}{c}\text { Cy 3- } \\
\text { rutinoside }\end{array}$ & $\begin{array}{c}\text { Cy 3- } \\
\text { glucoside }\end{array}$ & $\begin{array}{l}\text { D 3- } \\
\text { rutinoside }\end{array}$ & $\begin{array}{c}\text { Cy 3- } \\
\text { xylosyl- } \\
\text { rutinoside }\end{array}$ & $\begin{array}{c}\text { Cy 3- } \\
\text { xyloside }\end{array}$ & $\begin{array}{c}\text { Cy 3- } \\
\text { (6"-dioxalyl- } \\
\text { glucoside) }\end{array}$ & $\begin{array}{c}\text { Cy 3- } \\
\text { (6"-succinyl- } \\
\text { glucoside) }\end{array}$ \\
\hline \multirow{4}{*}{ FDB } & RB & $744 \pm 60$ & & $676 \pm 7^{*}$ & & & & & \\
\hline & BB & & & $3255 \pm 57$ & & & $145 \pm 33$ & $157 \pm 50$ & $109 \pm 28$ \\
\hline & $\mathrm{RC}$ & & & & $427 \pm 33$ & $1145 \pm 22$ & & & \\
\hline & $B C$ & & $2512 \pm 282$ & & $2305 \pm 40$ & & & & \\
\hline \multirow{4}{*}{ DB -50} & $\mathrm{RB}$ & $420 \pm 41$ & & $380 \pm 29 *$ & & & & & \\
\hline & BB & & & $713 \pm 24$ & & & $27.7 \pm 1$ & $15.1 \pm 0$ & \\
\hline & RC & & & & $53 \pm 5$ & $341 \pm 34$ & & & \\
\hline & $B C$ & & $2338 \pm 64$ & & $2227 \pm 14$ & & & & \\
\hline \multirow{4}{*}{ DB -65} & $\mathrm{RB}$ & $187 \pm 14$ & & $148 \pm 52 *$ & & & & & \\
\hline & BB & & & $882 \pm 12$ & & & $1 \pm 0$ & $65 \pm 0$ & $23 \pm 0$ \\
\hline & $\mathrm{RC}$ & & & & $52 \pm 0$ & $229 \pm 1$ & & & \\
\hline & $B C$ & & & & & & & & \\
\hline \multirow{4}{*}{ DB - 130} & $\mathrm{RB}$ & & & & & & & & \\
\hline & BB & & & $37 \pm 12$ & & & $12 \pm 1$ & $5 \pm 0$ & $21 \pm 0$ \\
\hline & RC & & & & & & & & \\
\hline & $B C$ & & $8 \pm 0$ & & $6 \pm 0$ & & & & \\
\hline
\end{tabular}

FDB: freeze-dried berry, DB-50: air-dried berry at $50{ }^{\circ} \mathrm{C}, \mathrm{DB} 65$ : air-dried berry at $65^{\circ} \mathrm{C}, \mathrm{DB} 130$ : air dried berry at $130{ }^{\circ} \mathrm{C}, \mathrm{RB}$ : raspberry, $\mathrm{BB}$ : boysenberry, RC: redcurrant and $\mathrm{BC}$ : blackcurrant. Mean $\pm S D(n \geq 3)$. Numbers in the table are in bold to show the most abundant anthocyanin in each sample, while white spaces correspond to not quantifiable anthocyanin. Within the same column, value with different letters indicate significant differences $(\mathrm{P}<0.05)$. Nd: not detectable.

*In RB Cy 3-glucoside co-eluted with Cy 3-rutinoside. 
Table 6.- Total polyphenol content in acetone and methanolic extracts of dried berries*

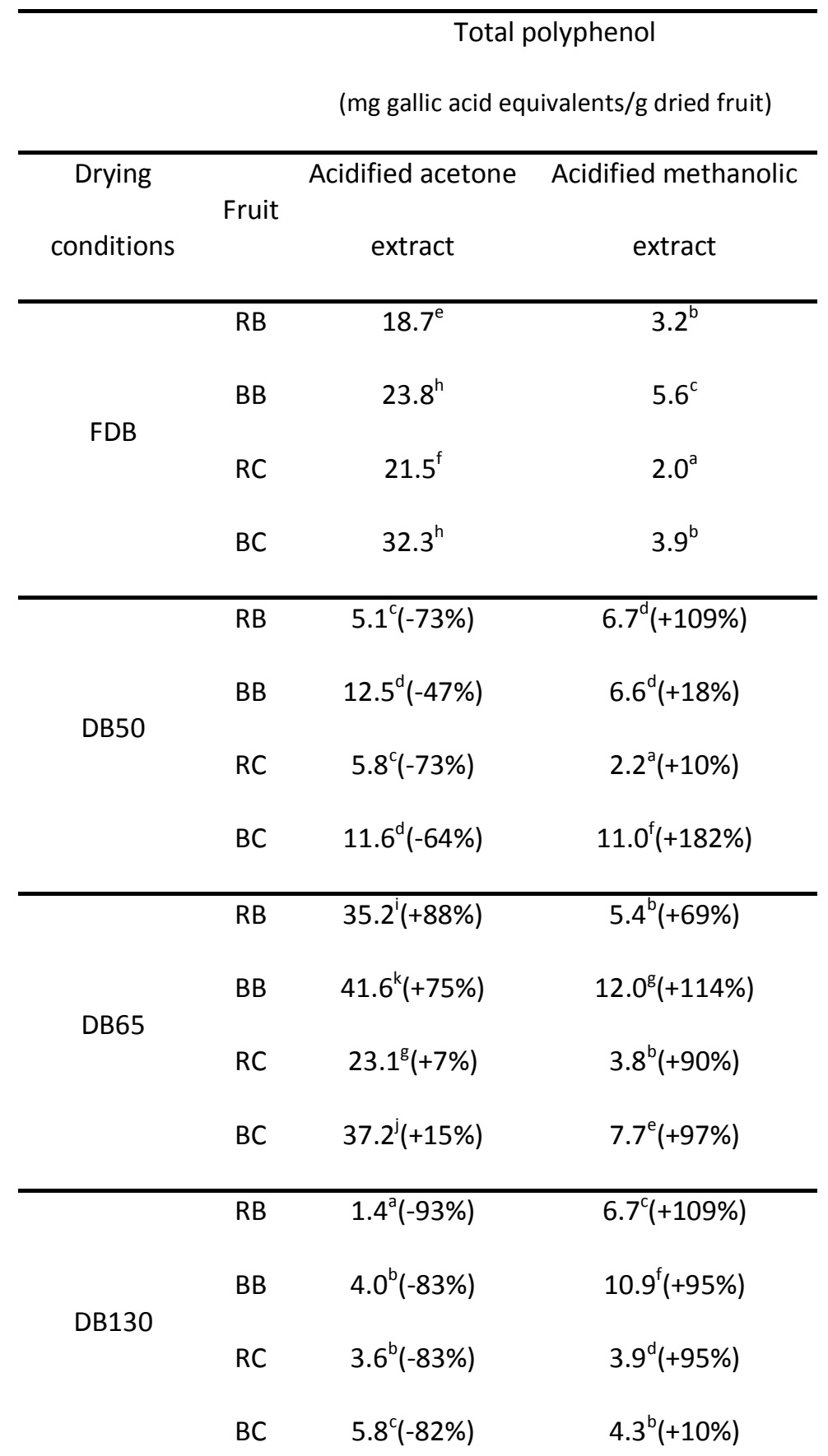

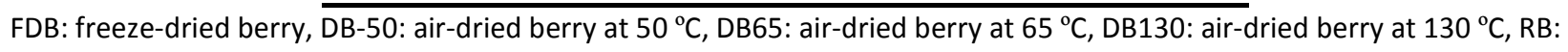
raspberry, BB: boysenberry, RC: redcurrant and BC: blackcurrant.

*Within the same column, values with different letters indicate significant differences $(P<0.05)$

Values between parentheses indicate percentage of increase or decrease with respect to FDB. 


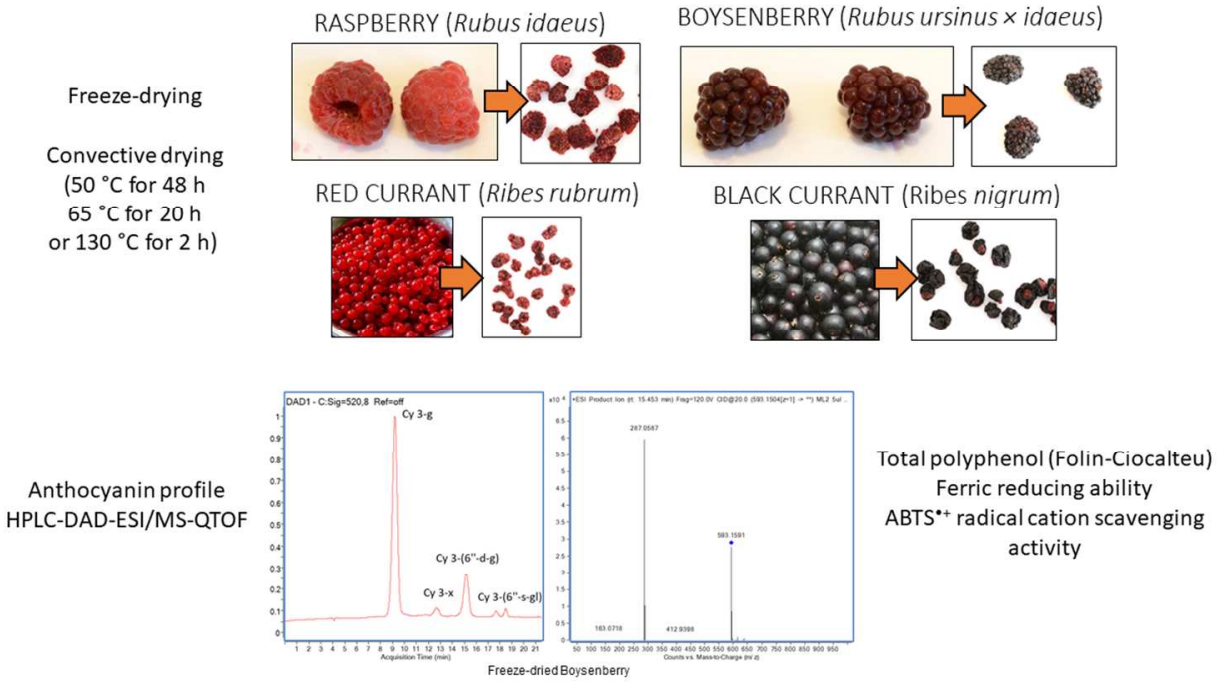

TOC Graphic

$338 \times 190 \mathrm{~mm}(96 \times 96 \mathrm{DPI})$ 